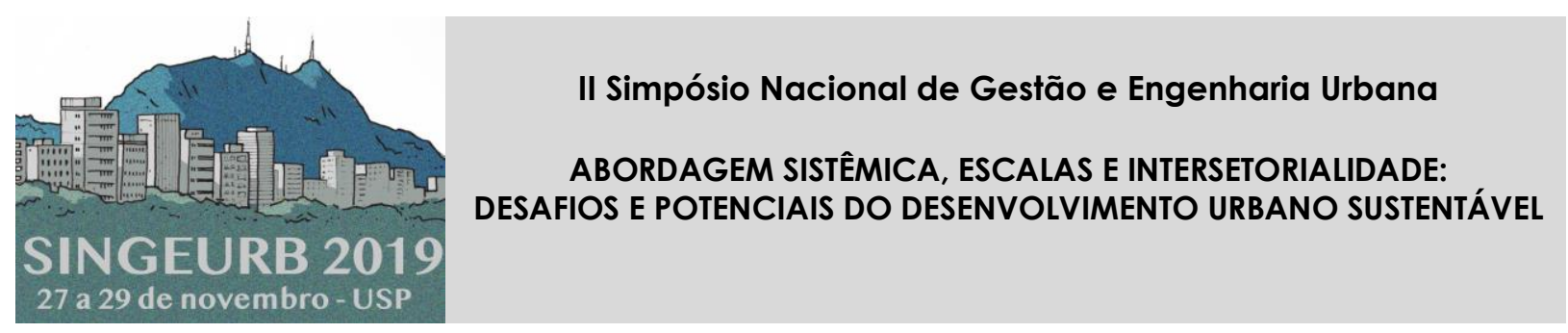

\title{
Aplicação de indicador de sustentabilidade urbana para avaliação de áreas verdes: estudo na cidade de Vitória-ES 1
}

\section{Application of urban sustainability indicator for evaluation of green areas: study in the city of Vitória-ES}

\author{
Fernandes, Stella Fafá de Carvalho'; Bonatto, Daniella do Amaral Mello² \\ Universidade Federal do Espírito Santo-UFES/Departamento de Arquitetura e \\ Urbanismo, Av. Fernando Ferrari, 514, Goiabeiras. Vitória-ES, Brasil, \\ stellafafa@gmail.com² \\ 2 Universidade Federal do Espírito Santo-UFES/Departamento de Arquitetura e \\ Urbanismo, daniella.bonatto@ufes.br
}

\begin{abstract}
RESUMO
A qualidade dos espaços livres públicos de um centro urbano está diretamente ligada à qualidade de vida que proporciona. Dentre os diferentes tipos de espaços livres - como ruas, praças, parques - as áreas verdes são um grupo específico, que presta serviços ecossistêmicos aos núcleos urbanos: amenização da temperatura, aumento da umidade relativa do ar, diminuição das ilhas de calor, drenagem urbana, bem-estar, dentre outros. Existem diversos Indicadores para avaliar as áreas verdes, de modo a monitorar e estimular o desenvolvimento urbano sustentável. Este trabalho, fruto de uma Iniciação Científica, tem como objetivo avaliar a aplicabilidade do indicador "Porcentagem de área verde em relação à área local" (SBTool PT), procurando observar deficiências e sugerir adequações. As etapas metodológicas envolveram levantamento de dados, elaboração de fichas e mapas, aplicação de indicador e análise dos resultados e da aplicação. Foram tomadas duas escalas de análise - municipal (Vitória, ES) e de bairro (Jardim da Penha). Observou-se que a avaliação quantitativa proposta pelo indicador foi insuficiente. Observou-se, ainda, a necessidade de adequação dos parâmetros de sustentabilidade da ferramenta. Este trabalho espera contribuir para a discussão de indicadores de sustentabilidade e sua adequação à realidade brasileira.
\end{abstract}

Palavras-chave: Sistema de espaços livres, Indicadores, Sustentabilidade urbana, Espaços livres públicos, Áreas verdes.

\footnotetext{
ABSTRACT

The quality of public open spaces in an urban centre is directly linked to the quality of life that it provides. Among the different types of free spaces - such as streets, squares, parks - the green areas are a specific group, which provide ecosystems services to urban centres: temperature mitigation, increase in relative humidity, decrease in heat islands, urban drainage, well-being,

${ }^{1}$ FERNANDES, Stella F. C.; BONATTO, Daniella do A. M. Aplicação de indicador de sustentabilidade urbana para avaliação de áreas verdes: estudo na cidade de Vitória-ES. In: II SIMPÓSIO NACIONAL DE GESTÃO E ENGENHARIA URBANA: SINGEURB, 2019, São Paulo. Anais... Porto Alegre: ANTAC, 2019. 
among others. There are several indicators for assessing green areas in order to monitoring and stimulate sustainable urban development. This work, a result of a Scientific Initiation, aims to evaluate an indicator developed by the SBTool - "Percentage of Green Area in Relation to the Local Area", pointing out the needs and proposing adjustments. Methodological steps involved data collection, preparation of charts and maps, application of indicator and analysis of results and its applicability. There were two scales of analysis - municipal (Vitória, ES) and neighbourhood (Jardim da Penha). It has been observed that the purely quantitative evaluation propose for the tool was insufficient, as well that sustainability parameters of the tool needs adequacy. This paper aims to contribute to the discussion and adaptation of sustainability indicators to the Brazilian reality.

Keywords: Open spaces system, Indicators, Urban sustainability, Public open spaces, Green areas.

\section{INTRODUÇÃO}

A qualidade dos espaços livres dos centros urbanos está diretamente ligada à qualidade de vida que proporcionam. Estes espaços compõem a paisagem e ofertam áreas para práticas sociais, contato com a natureza, exercícios físicos e lazer. Ainda, são capazes de amenizar os efeitos causados pelas atividades humanas e contribuir para a um meio ambiente urbano mais sustentável e equilibrado.

Compreendendo o papel ambiental, paisagístico e recreativo que os espaços livres e áreas verdes exercem no meio ambiente urbano, a criação e preservação desses espaços são pautas do Urbanismo Sustentável, onde a inclusão dos elementos naturais é essencial para a sustentabilidade e qualidade de vida:

A proximidade residencial com a natureza pode estar relacionada a fatores que contribuem para a saúde, como a redução da poluição atmosférica e da polvição sonora e pode fornecer exposição "indireta" através da visibilidade a partir da residência. A proximidade residencial também está positivamente relacionada à exposição "direta", ou seja, as pessoas em bairros mais verdes tendem a relatar visitas a espaços verdes mais frequentes. (WHITE et al, 2019, tradução nossa)

Diversas ferramentas de avaliação da sustentabilidade urbana apresentam Indicadores para subsidiar o planejamento, o desenho urbano e políticas públicas, permitindo avaliar e certificar o nível de sustentabilidade de um território nos campos ambiental, social e econômico. Entretanto, a disparidade das realidades dos países desenvolvidos e dos países em desenvolvimento demanda adaptações (BRAGANÇA et al, 2017). A aplicação desses indicadores em países da América Latina e Caribe sem os devidos ajustes mostra-se inviável devido à inadequação dos parâmetros propostos pelas ferramentas.

Este artigo buscou avaliar a aplicabilidade do indicador "Porcentagem de área verde em relação à área local", elaborado pela ferramenta SBTool PT - Ferramenta para a avaliação e Certificação da Sustentabilidade da Construção, apontando suas deficiências e sugerindo adequações, de modo a contribuir para o aperfeiçoamento da análise.

\section{ESPAÇOS LIVRES PÚBLICOS - ÁREAS VERDES E SUSTENTABILIDADE}

A quantidade e qualidade dos espaços públicos ocupa papel central para a densidade urbana, necessária para a sustentabilidade (ONU-Habitat, 2012). As áreas verdes públicas constituem elemento essencial da qualidade do ambiente urbano. Os espaços livres públicos e as áreas verdes, especialmente de recreação, têm poder de conectar o tecido urbano e as pessoas. Da mesma forma, uma boa oferta e distribuição de áreas verdes e espaços verdes de recreação é condição para a sustentabilidade urbana e ambiental, tendo especial papel na redução das desigualdades socioespaciais, devendo ser monitorada, avaliada e objeto de políticas públicas de desenvolvimento urbano. A incorporação do tema ambiental no planejamento urbano é produto da união das pautas sociais com a ambiental, que 
anteriormente caminhavam em separado, eventualmente convergindo. Esta nova forma de enxergar o urbano direciona as propostas de intervenção:

O urbanismo sustentável chama atenção para a oportunidade enorme de redesenhar o ambiente construído de uma maneira que sustente uma maior qualidade de vida e promova um estilo de vida saudável e sustentável [...]. A base para essa transformação do ambiente construído é síntese do urbanismo - a tradição milenar de assentamentos humanos - com o ambientalismo do final do século XX [...]. (FARR, 2013, p. 13)

Ao se estudar o campo ambiental de um dado território sob o viés do urbanismo sustentável, depara-se com a análise de áreas verdes e espaços livres, elementos diferem entre si. Espaços livres públicos são locais livres de edificação. Áreas verdes são zonas onde os elementos vegetativos são estruturantes e predominantes visualmente, sendo que essas áreas fazem parte dos espaços livres. Um conjunto formado por esses elementos e suas diferentes relações de hierarquia, conectividade e funções, configuram um sistema:

Os espaços livres urbanos formam um sistema, apresentando, sobretudo, relações de conectividade, complementaridade e hierarquia. Entre seus múltiplos papéis, por vezes sobrepostos, estão a circulação, a drenagem, atividades do ócio, convívio público, marcos referenciais, memória, conforto e conservação ambiental etc. O sistema de espaços livres de cada cidade apresenta um maior ou menor grau de planejamento e projeto prévio, um maior ou menor interesse da gestão pública num ou noutro sub-sistema a ele relacionado. (QUEIROGA \& BENFATTI, 2007, p. 81-88)

Através do urbanismo sustentável, busca-se a preservação, manutenção e estruturação desses espaços em centro urbanos, à medida que se entende seu papel na defesa de um desenvolvimento urbano equilibrado para a garantia de qualidade de vida.

\section{METODOLOGIA}

Com o intuito de avaliar a aplicabilidade de indicadores de sustentabilidade com foco em espaços livres e áreas verdes, a pesquisa que originou este artigo contou com a etapa preliminar seleção de ferramentas e seus respectivos indicadores (BONATTO et al, 2018). Posteriormente, foram elaboradas fichas descritivas de cada indicador a partir dos dados das ferramentas selecionadas. Quando inexistentes, os dados foram formulados pela pesquisa de modo a complementar as informações necessárias para a aplicação.

Este artigo aborda apenas um dos indicadores de Ecologia e Biodiversidade da ferramenta SBTOol PT: "Porcentagem de Área Verde em Relação à Área Local". Todas as informações necessárias estavam disponíveis no Manual de Avaliação - Metodologia para Planeamento Urbano (2014), dispensando complementações por esta pesquisa. O objeto de análise foi Vitória-ES, apresentando-se a aplicação do indicador nas escalas municipal e do bairro Jardim da Penha, com enfoque exclusivo nas áreas verdes públicas. 
Figura 1 - Mapa do Município de Vitória e do bairro de Jardim da Penha

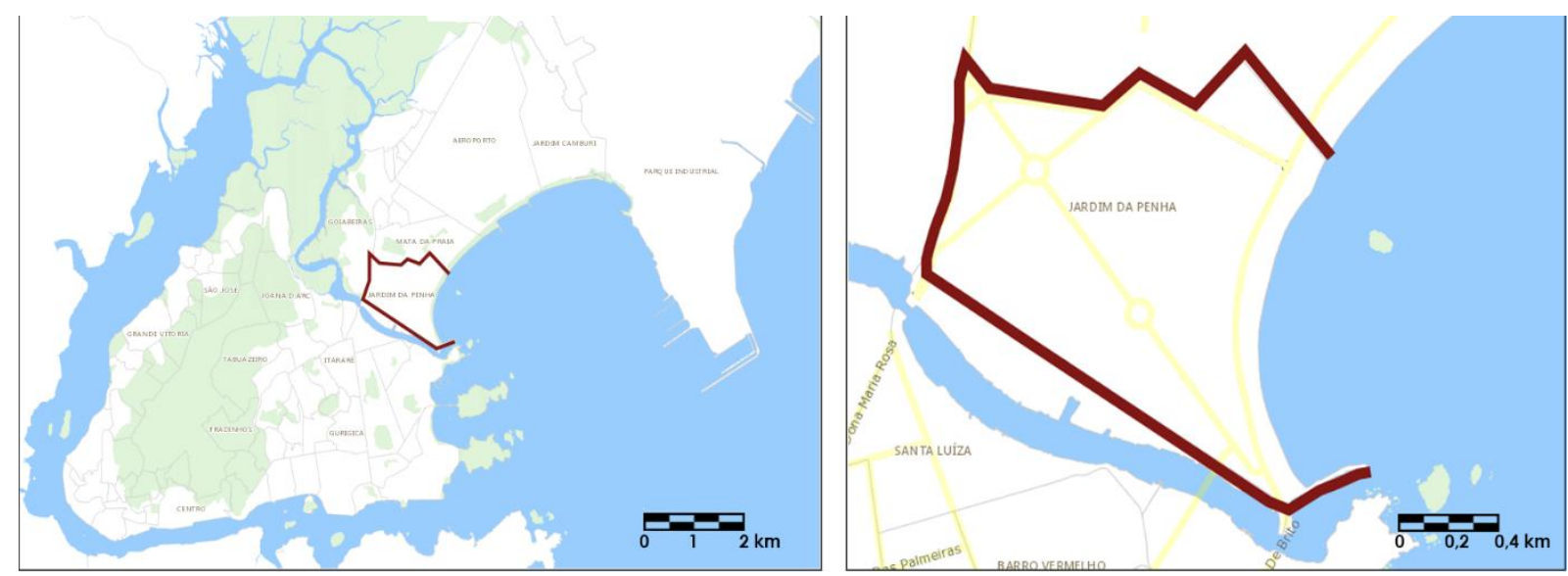

Fonte: Geoweb/PMV, 2018. Editado pelos autores.

A relevância de se estudar o município de Vitória se dá pela necessidade de evidenciar um problema que se esconde nas análises puramente quantitativas. Apesar de o município dispor de grande quantidade de áreas verdes, estas se apresentam de forma concentrada, sobretudo no Maciço Central, existindo diversos bairros mal servidos. O bairro Jardim da Penha foi escolhido por ser um bairro planejado, com boa distribuição de praças e arborização urbana, além de ser dos mais populosos do município, com população de 30.571 habitantes do total 319.163 de Vitória.

\section{1 Áreas verdes}

O indicador faz parte da categoria Ecologia e Biodiversidade e tem como objetivo "promover a continuidade ecológica dentro dos centros urbanos, contribuindo deste modo para a melhoria da qualidade do ar e criando, ao mesmo tempo, espaços de lazer para a população". O termo "espaços verdes" refere-se aos "[...] espaços de caráter público ou privado que possuem vegetação como elemento estruturante, o que abrange praças, jardins públicos, jardins privados e parques urbanos" (SBToolPT, 2014, p. 48).

A aplicação deste indicador no município de Vitória e no bairro de Jardim da Penha demandou diferentes informações disponíveis no site da Prefeitura. Sobre a base do Município em dwg, foram importados os shapes das praças da cidade. Na escala municipal, foram adicionadas as áreas verdes apontadas pelos arquivos da Prefeitura, que incluem as diferentes tipologias: Área de Proteção Ambiental, Área de Preservação Permanente, Área Verde Especial, Parque Urbano Municipal, Parque Estadual, Reserva Ecológica Municipal, Parque Natural Municipal, Estação Ecológica. Por Vitória ser cidade litorânea, as orlas (calçadão e faixa de areia) foram incluídas como tipologia de áreas verdes.

A seguir, apresenta-se a metodologia utilizada.

\subsubsection{Porcentagem de áreas verdes}

Inicialmente foi realizado o cálculo da porcentagem de área verde em relação à área local.

\subsubsection{Benchmark e normalização}

Em seguida, o valor encontrado na etapa anterior foi comparado aos valores de melhor prática e prática convencional (Quadro 1) e posteriormente inserido na fórmula de normalização (Equação 1): 
Quadro 1 - Benchmark

\begin{tabular}{|c|c|}
\hline Melhor Prática: & Dev $*=42$ \\
\hline Prática Convencional: & Dev $\#=8$ \\
\hline Projeto: & Dev $=$ \\
\hline
\end{tabular}

Fonte: SBTool PT (2014)

$\underline{D e v}=\frac{D e v-D e v \#}{D e v *-D e v \#}$

\subsubsection{Marcas de referência}

Por fim, através da Marcas de Referência (Quadro 2) foi possível classificar o território segundo a quantidade de áreas verdes de que dispõe:

Quadro 2 - Marcas de Referência

\begin{tabular}{|c|c|c|}
\hline Nível & Condições & $\checkmark$ \\
\hline A + & $\underline{D e v}>1,00$ & \\
\hline A & $0,70<\underline{D e v} \leq 1,00$ & \\
\hline B & $0,40<\underline{\text { Dev }} \leq 0,70$ & \\
\hline C & $0,10<\underline{D e v} \leq 0,40$ & \\
\hline D & $0,00<\underline{D e v} \leq 0,10$ & \\
\hline E & $\underline{D e v}<0,00$ & \\
\hline
\end{tabular}

Fonte: SBTool PT (2014)

\section{RESULTADOS E DISCUSSÕES}

O município de Vitória $\left(93,38 \mathrm{~km}^{2}\right)$ apresenta $39,12 \%$ de seu território formado por áreas verdes, classificando-se como nível A em sustentabilidade. O bairro de Jardim da Penha $\left(1,46 \mathrm{~km}^{2}\right)$ entretanto, obteve o nível $D$ em sustentabilidade, sendo apenas $9,7 \%$ de seu território constituído de áreas verdes públicas. A inclusão das áreas verdes privadas certamente aumentaria essa porcentagem. Entretanto, são de difícil aferição e não prestam serviço à socialização da população.

\subsection{Análise}

Quanto à coleta de dados, é necessário destacar que a Prefeitura de Vitória possui um site com bom acervo de informações, de fácil acesso, suficientes para a aplicação deste indicador, dispensando a coleta de dados in loco. O município de Vitória obteve um ótimo desempenho segundo a "Marca de Referência" proposta pela ferramenta. A cidade apresenta 114,47 $\mathrm{m}^{2} / \mathrm{hab}$ de áreas verdes. Em contrapartida, apesar de Jardim da Penha ser considerado um dos bairros que apresentam as melhores ofertas de espaços livres e verdes no município, o bairro obteve um baixo desempenho, apresentando $4,63 \mathrm{~m}^{2} / \mathrm{hab}$ de área verde. Para complementar, foi necessário analisar os mapas onde estão destacadas as áreas verdes de cada escala de aplicação (Figuras 2 e 3). 
Figura 2 - Áreas verdes no município de Vitória - ES

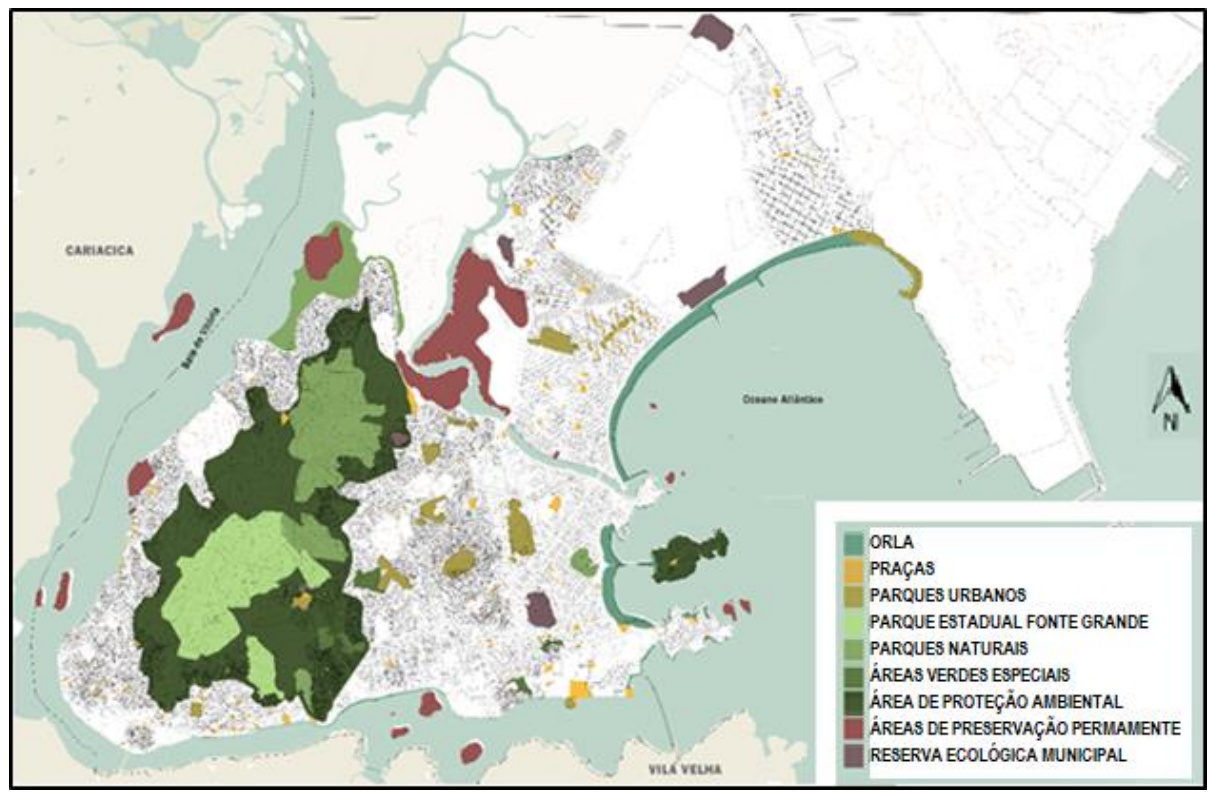

Fonte: PMV, 2018. Complementado e editado pelas autoras (2019)

Figura 3 - Áreas verdes no bairro de Jardim da Penha

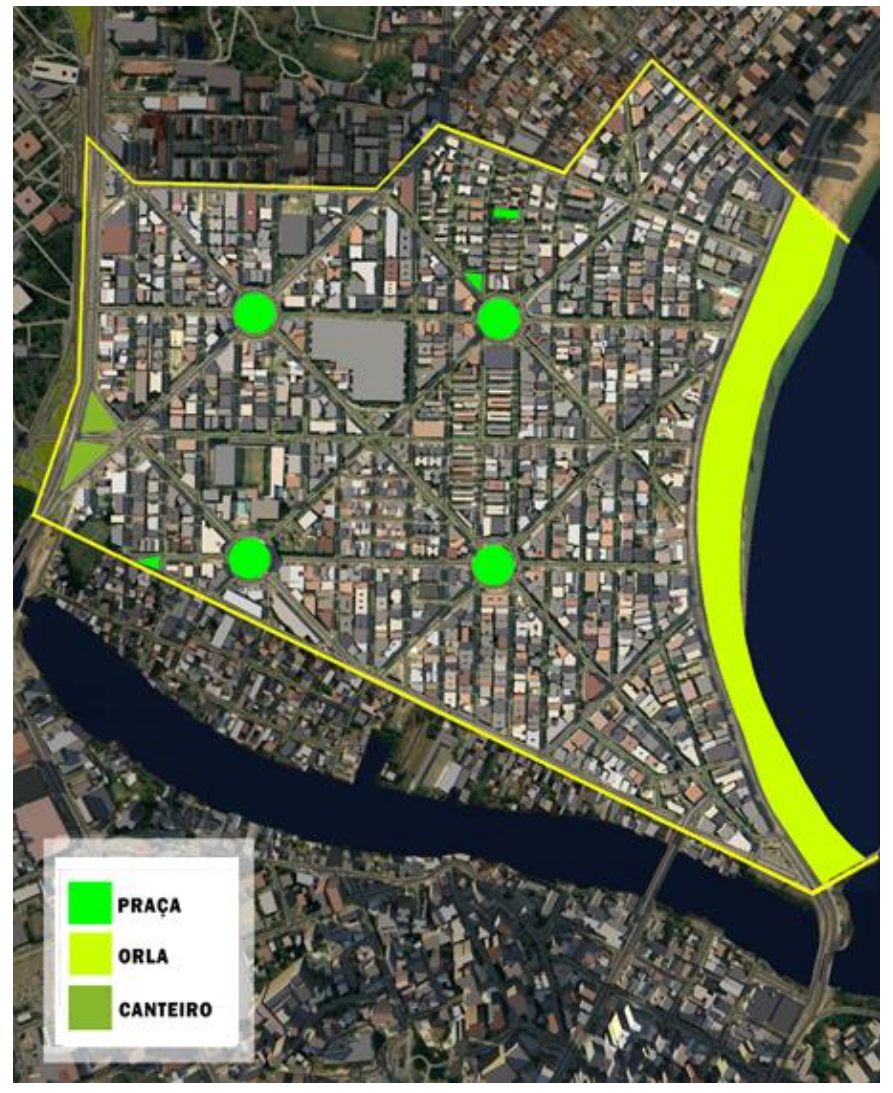

Fonte: As autoras (2019)

Apesar do ótimo desempenho quantitativo obtido pelo município, quando analisada a distribuição das áreas verdes (Figura 2) observa-se uma grande concentração $(28,75 \%)$ no Maciço Central, área montanhosa e pouco acessível. Contudo, apesar do baixo desempenho quantitativo de Jardim da Penha (Figura 3), há uma distribuição uniforme das praças pelo bairro, que foi planejado, sendo bastante acessíveis e utilizadas. 
Apesar da metodologia fornecida pela ferramenta não considerar "orlas" como áreas verdes, a orla é elemento estruturante em Vitória e consegue atender ao objetivo do indicador, de promover a continuidade ecológica, contribuindo para a melhoria da qualidade do ar e criando espaços de lazer para a população. As orlas são componentes naturais no meio urbano, que exercem função ambiental, de desportiva e recreacional.

\section{CONSIDERAÇÕES E CONCLUSÕES}

Este indicador foi de fácil aplicação devido à disponibilidade de informações pela Prefeitura de Vitória e pela clareza da metodologia de cálculo fornecida pela ferramenta. É recomendável uma ampliação do conceito de áreas verdes da ferramenta para que englobe outras tipologias, como "orlas".

A avaliação proposta pelo indicador se mostrou superficial por não avaliar a qualidade dos espaços, apenas quantificar a oferta. Recomenda-se sua complementação por uma análise qualitativa dessas áreas. Esta necessidade pode ser comprovada pela análise da morfologia, que apontou outras características nas duas escalas. É indispensável uma análise mais detalhada das áreas verdes para que estes possam contribuir de fato com território onde estão inseridos.

Além disto, as áreas verdes aqui abordadas limitam-se a espaços pontuais de uma cidade espaços livres de permanência (praças, parques, jardins públicos). Entretanto, ampliar este conceito, abrangendo o elemento rua como integrante dos espaços livres, permite considerar a conectividade entre os espaços pontuais através destes elementos lineares e com isso, estendemos a discussão para um estudo mais profundo do sistema de espaços livres.

\section{AGRADECIMENTOS}

Agradecemos à FAPES pelo apoio à pesquisa que originou este artigo.

\section{REFERÊNCIAS}

BONATTO, Daniella do A. M.; ROCHA, Jaqueline S.; FERNANDES, Stella F. C. Áreas verdes públicas como fator de sustentabilidade urbana: estudo de indicadores. In: Congresso Internacional 'Sustentabilidade Urbana' - 14a Jornada Urbenere e 2a Jornada CIRES, 2018 , Vila Velha. Anais... Vila Velha: Editores, 2018. v. 2., p. 1227-1236.

BRAGANÇA, LUís, CONDE, Karla, ALVAREZ, Cristina E. Proposta de indicadores de avaliação de sustentabilidade urbana para países Latino-americanos. In: Anais... Lisboa: iiSBE Portugal \& Universidade do Minho, 2017. pp. 85-94.

FARR, Douglas. Urbanismo Sustentável: desenho urbano com a natureza. Porto Alegre: Bookman, 1a. ed., 2013.

ONU-Habitat. Estado de las ciudades de América Latina y el Caribe 2012 Rumbo a una nueva transición urbana. Rio de Janeiro: Programa de las Naciones Unidas para los Asentamientos Humanos, 2012.

QUEIROGA, E.; BENFATTI, D. Sistemas de espaços livre urbanos: construindo um referencial teórico. Paisagem e Ambiente, n. 24, p. 81-87, 31 dez. 2007.

SBTool PT - STPU (2014). Manual de Avaliação - Metodologia para Planeamento Urbano. Consórcio: ECOCHOICE; Universidade do Minho - Laboratório de Física e Tecnologia. Versão distribuída à Comissão Técnica do iiSBE PT.

WHITE, Mathew P., ALCOCK, lan, GRELIER, James, WHEELER, Benedict W., HARTIG, Terry, WARBER, Sara L., BONE, Angie, DEPLEDGE, Michael H., FLEMING, Lora E. Spending at least 120 
minutes a week in nature is associated with good health and wellbeing. Scientific Reports, vol.9:7730, 2019. Disponível em https://doi.org/10.1038/s41598-019-44097-3. Acessado 18/06/2019. 